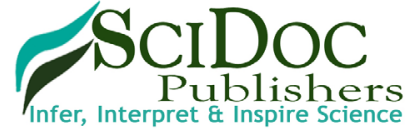

\title{
International Journal of Surgery and Research (IJSR)
}

ISSN 2379-156X

\section{Clinical Outcomes of Orbital Trauma in South Australia}

Research Article

Surman $\mathrm{TL}^{1 *}$, Mourik $\mathrm{KV}^{2}$, Sambrook $\mathrm{PJ}^{3}$, Goss $\mathrm{A}^{4}$

${ }^{1}$ Surgical Registrar Royal Adelaide Hospital, Oral and Maxillofacial Surgery Department, Royal Adelaide Hospital, Adelaide, South Australia.

${ }^{2}$ Oral and Maxillofacial Surgery Registrar Oral and Maxillofacial Surgery Department, Royal Adelaide Hospital, Adelaide, South Australia.

${ }^{3}$ Associate Professor, Head of Oral and Maxillofacial Surgery; Oral and Maxillofacial Surgery Department, Royal Adelaide Hospital, Adelaide, South Australia.

${ }^{4}$ Emeritus Professor of Oral and Maxillofacial Surgery; Oral and Maxillofacial Surgery Department, Royal Adelaide Hospital, Adelaide, South Australia.

\section{Abstract}

Introduction: Our primary aims are to report on the demographics of orbital trauma in Adelaide, South Australia. Our secondary aims are to demonstrate the long-term (>12 months) clinical outcomes of orbital trauma patients.

Materials and Methods: Forty patients agreed to participate in the study, including 20 surgical patients and 20 non-operative patients. Patients were assessed in the areas of demographics, sensory, visual and cosmetic outcomes.

Results: In the surgical patient group, $13 / 20(65 \%)$ patients suffered trauma from physical assault and 16/20 (80\%) were males. In the non-surgical patient group, $17 / 20(85 \%)$ suffered trauma from physical assault and 16/20 (80\%) were males. In the surgical patient group, sensory deficit was reported in $8 / 20$ patients $(40 \%)$, visual deficit was reported in $8 / 20$ patients $(40 \%)$, and cosmetic deficit was reported in $6 / 20(30 \%)$ patients. In the non-operative patient group, sensory deficit was reported in $7 / 20$ patients $(35 \%)$, visual deficit was reported in $8 / 20$ patients $(40 \%)$ and cosmetic deficit was reported in $6 / 20$ patients $(30 \%)$.

Conclusion: Our clinical study of 40 patients showed no clear clinical or statistical difference between outcomes in the two groups. Impaired visual, sensory and cosmetic deficits were reported in the minority and did not impact on quality of life.

Keywords: Orbital Trauma; Demographics; South Australia.

\section{Background}

The Royal Adelaide Hospital (RAH) is a major facial trauma centre, treating patients from both South Australia and the Northern Territory. Orbital wall fractures represent a significant portion of the total workload, compromising approximately $40 \%$ of all facial fractures. Appropriate surgical management of orbital wall fractures is imperative to avoid both functional sequelae (blindness, diplopia, infraorbital nerve dysfunction, nasolacrimal outflow tract dysfunction) and cosmetic sequelae (enophthalmos, dystopia, facial asymmetry) that may impair vision, reduce ability to work, and decrease quality of life $[1,6,8]$.

When indicated, surgical management involves reconstruction of the orbital wall fracture defect with either autogenous bone or alloplastic material. By re-establishing the continuity and contour of the orbital walls, this restores support for the globe and intraorbital soft tissue and treats/prevents sequelae like enophthalmos, dystopia, and diplopia [1-11].

\section{Materials and Methods}

Participants were recruited from the Oral and Maxillofacial Surgery Unit, Adelaide, South Australia online trauma database. Two study groups comprising surgical and non-operative patients were recruited with isolated orbital floor fractures. A total of 298 orbital fracture cases were reviewed over a period from 20082015. All 298 cases were attempted to be contacted via telephone to participate in the study, however only 40 patients agreed; which included 20 surgical and 20 non-operative trauma patients.

Clinical examinations of both surgical and non-operative patients used three core parameters; sensation, vision and physical characteristics. Sensation was tested using dental examination instruments (dental explorer, dental probe) testing sensory modalities. Vision was tested via subjective questions and answers.

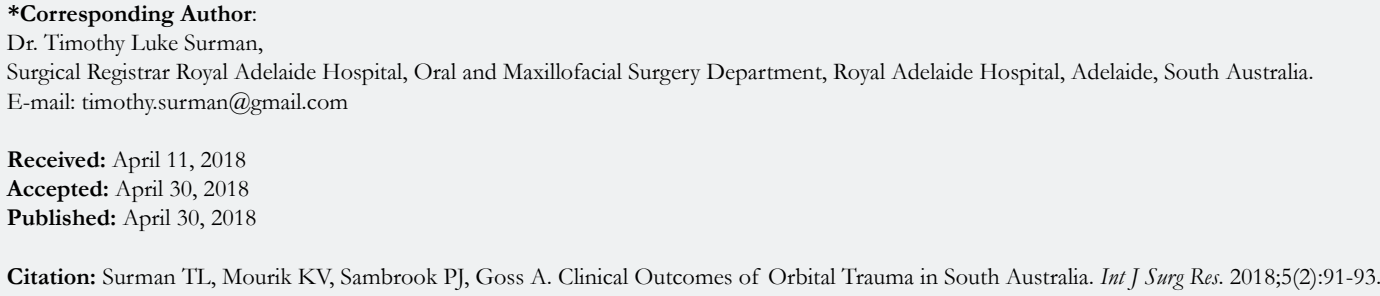

Copyright: Surman TL $^{\circ}$ 2018. This is an open-access article distributed under the terms of the Creative Commons Attribution License, which permits unrestricted use, distribution and reproduction in any medium, provided the original author and source are credited. 
Physical effects such as enophthalmos or exophthalmos was testing using a Hertels Exophthalmometer. Values were recorded in millimetres and compared to the contralateral side. All patients consented to this study verbally and in written format.

A chi square test was used to determine if there was any trends or statistically significant differences in complication rates between the surgical and non-operative groups.

\section{Results}

In surgical patients, $13 / 20(65 \%)$ were from physical assault, $4 / 20(20 \%)$ were from falls, and $3 / 20(15 \%)$ from motor vehicle accidents. Fifteen of the 20 patients were male $(75 \%)$. Fifteen of the 20 patients had right-sided fractures $(75 \%)$.

In non operative patients, $15 / 20(75 \%)$ were from physical assault, $2 / 20(10 \%)$ from falls, and $1 / 20(0.5 \%)$ from motor vehicle accident. Sixteen of the 20 patients were male $(80 \%)$. Sixteen of the 20 patients had right sided fractures $(80 \%)$.

In surgical patients, sensory deficit was described in $9 / 20$ patients $(45 \%)$. Numbness around the site of trauma was the most commonly reported in $6 / 20$ cases $(30 \%)$. Visual deficit was described in $8 / 20$ patients $(40 \%)$. Increased tear flow in $5 / 20$ cases $(25 \%)$ was most commonly reported. Physical deficit was observed in $6 / 20(30 \%)$. Minor scar as a result of the injury was most common in $2 / 20$ cases $(10 \%)$. Diplopia was reported in $1 / 20$ patients $(5 \%)$, and no evidence of enophthalmos or exophthalmos was reported.

In non-operative patients, sensory deficit was described in $7 / 20$ patients $(35 \%)$. Numbness around the site of trauma was the most commonly reported in $4 / 20$ cases $(20 \%)$. Visual deficit was described in $8 / 20$ patients $(40 \%)$. Increased tear flow was most commonly reported in $5 / 20$ cases $(25 \%)$. Physical deficit was observed in $5 / 20$ patients $(25 \%)$. Loss of cheek contour was most commonly seen and reported in $5 / 20$ cases $(25 \%)$. No diplopia or enophthalmos or exophthalmos was reported. No post trauma sensory, visual or physical deficits were reported on the contralateral side.

There was no trends or statistically significant differences in complication rates between the non-operative and surgical cohorts. A critique of the clinical and statistical conclusions include reduced patient numbers and as a result, low study power (Table 1).

\section{Conclusion}

In our clinical study of orbital trauma patients in Adelaide, South Australia no clear clinical or statistical difference is seen between patients managed conservatively or surgically in orbital fracture trauma. Outcomes in both groups were satisfactory and quality of life for all patients was maintained.

Further investigation is required with greater patient numbers and longer follow up to investigate the clinical effects of surgical and non-operative management of orbital trauma.

Despite the presence of minor clinical adverse effects, the surgeon still needs to take into account the risk benefit and individual patient factors in the management of orbital trauma.

Table 1. Statistical analysis of surgical and non-operative cohorts.

\begin{tabular}{|c|c|c|}
\hline & p value & chi-squared \\
\hline SENSATION & \multicolumn{2}{|l|}{} \\
\hline Numbness & 0.465 & 0.533 \\
\hline Pricking & 0.677 & 0.173 \\
\hline Hyperaesthesia & 0.468 & 0.526 \\
\hline Pain & 0.705 & 0.143 \\
\hline VISION & \multicolumn{2}{|l}{} \\
\hline Blurred vis on & 0.167 & 1.905 \\
\hline Diplopia & 0.311 & 1.026 \\
\hline Increased tear flow & 0.705 & 0.143 \\
\hline Photosensitivity & 1 & 0 \\
\hline Blindness & 1 & 0 \\
\hline PHYSICAL & & \\
\hline Scar & 1 & 0 \\
\hline Eno/Exophthalmos & 1 & 0 \\
\hline Ectropion & 1 & 0 \\
\hline Loss of Cheek contour & 0.429 & 0.625 \\
\hline Tics & 0.311 & 1.026 \\
\hline
\end{tabular}




\section{References}

[1]. Folkestad L, Westin T. Long-term sequelae after surgery for orbital floor fractures. Otolaryngol Head Neck Surg. 1999 Jun;120(6):914-21. PubMed PMID: 10352449.

[2]. Lukats O, Vízkelety T, Markella Z, et al. Measurement of orbital volume after enucleation and orbital implantation. PloS one. 2012 Dec 6;7(12):e50333. PubMed PMID: 23236368.

[3]. He D, Blomquist PH, Ellis E. Association between ocular injuries and internal orbital fractures. J Oral Maxillofac Surg. 2006 Apr;65(4):713-20. PubMed PMID: 17368368.

[4]. Goggin J, Jupiter DC, Czerwinski M. Simple Computed TomographyBased Calculations of Orbital Floor Fracture Defect Size Are Not Sufficiently Accurate for Clinical Use. J Oral Maxillofac Surg. 2015 Jan;73(1):112-6. PubMed PMID: 25511962.

[5]. Kolk A, Pautke C, Schott V, Ventrella E, et al. Secondary post-traumatic enophthalmos: high-resolution magnetic resonance imaging compared with multislice computed tomography in postoperative orbital volume measurement. J Oral Maxillofac Surg. 2007 Oct;65(10):1926-34. PubMed PMID: 17884517.
[6]. Kunz C, Sigron GR, Jaquiéry C. Functional outcome after non-surgical management of orbital fractures - the bias of decision-making according to size of defect: critical review of 48 patients. Br J Oral Maxillofac Surg. 2012 Sep;51(6):486-92. PubMed PMID: 23141199.

[7]. Dubois L, Steenen SA, Gooris PJ, Bos RR, Becking AG. Controversies in orbital reconstruction-III. Biomaterials for orbital reconstruction: a review with clinical recommendations. Int J Oral Maxillofac Surg. 2016 Jan;45(1):41-50. PubMed PMID: 26250602.

[8]. Mazock JB, Schow SR, Triplett RG. Evaluation of ocular changes secondary to blowout fractures. J Oral Maxillofac Surg. 2004 Oct;62(10):1298-302. PubMed PMID: 15452819.

[9]. Peacock ZS, Boulos T, Miller JB, et al. Orbital fractures and ocular injury: is a postoperative ophthalmology examination necessary?. J Oral Maxillofac Surg. 2014 Aug;72(8):1533-40. PubMed PMID: 24780607.

[10]. Tsao K, Cheng A, Goss A, Donovan D. The use of cone beam computed tomography in the postoperative assessment of orbital wall fracture reconstruction. J Craniofac Surg. 2014 Jul;25(4):1150-4. PubMed PMID: 24933305.

[11]. Yeatts RP. Measurement of globe position in complex orbital fractures. II. Patient evaluation utilizing a modified exophthalmometer. Ophthal Plast Reconstr Surg. 1992;8(2):119-25. PubMed PMID: 1520653. 